\title{
ANALYSIS AND TREATMENT OF REVERSE OSMOSIS (RO) REJECT FROM DYE INDUSTRIES USING ANAEROBIC BAFFLED REACTOR
}

\author{
B. Anup Nikhil ${ }^{1, *}$, S. Ramesh ${ }^{2}$, S. Dhanasekar ${ }^{3}$ and J. S. Sudarsan ${ }^{4}$ \\ Department of Civil Engineering, SRM University, Kattankulathur, Chennai-603203, India \\ *E-mail : anupnikhil93@gmail.com
}

\begin{abstract}
Reverse osmosis (RO) is one of the advanced wastewater treatment processes that remove the concentrate in the form of dissolved impurities in raw waste water. The treated reject released during the RO process remain a major polluting problem. The RO reject, with high solid concentration, needs maximum purification. It is one major problem prevailing in the dye industry where RO was mainly used as a tertiary treatment to achieve zero discharge effluent. Approximately one-third of the total quantity of wastewater concentration was rejected and collected as RO reject in dye industries. This concentrated $\mathrm{RO}$ rejects stream seems to be more toxic than non-treated wastewater. To overcome this difficulty anaerobic baffled wall reactor (ABR) study was initiated. It was necessary to find a potential solution to treat RO reject with by-product recovery as the existing methods for treating RO reject is open dumping in the sea, discharge in sewer or swamps, as a dewatering process, disposal in water bodies. ABR study was carried out in a lab scale using RO as a feeding material. In this investigation, the anaerobic bio treatment process was carried out to reduce the Biological Oxygen Demand (BOD) concentration. ABR has the advantage of operating at even reduced flow rates to ensure contact between the RO reject feed and micro-organism. As a result of anaerobic digestion, ABR will produce a biogas as a by-product. By investigating various characteristics, it was observed that there is a consequential percentage decrease in Biological oxygen demand (55\% - 80\%), Chemical oxygen demand (COD) (65\% - 80\%), Chlorides (75\% - 90\%) and Alkalinity $(75 \%-85 \%)$.
\end{abstract}

Keywords: RO rejects, Dye industries, Anaerobic Baffled Reactor, Activated Sludge.

@) RASĀYAN. All rights reserved

\section{INTRODUCTION}

Textile industries are major industries contributing a lot to the economic development of Tamilnadu and India. Dye processing units are one of the major processes in the textile industries which help in enhancing the economy of the particular district also. It has one major downside, that it imparts various dyeing effluents on the nearby water resources. It causes environment detrimental to water bodies with high salts and color substances like aniline, mauveine etc., and vast amounts of wastewater which contain lethal amounts of toxic organic residues are produced by various dye industries. Synthetic dyes are considered harder to treat since they contain complex fragrant atomic structure, which makes them sturdy and harder to biodegrade. ${ }^{1}$ It was assessed that more than 10000 unique synthetic dyes are currently being used and more than $7 \times 10^{5}$ tons of engineered dyes are created around the world on a yearly basis for consumption by the textile industry. It was estimated that approximately $2 \times 10^{5}$ tons of unrecovered dyes are consistently lost to the water effluents by this industry on a global level.

Textile industries required huge quantity of water; around 200 to $2000 \mathrm{~m}^{3}$ of water per day was utilized for processing of dyes in textile Industries. It results in the generation of the same vast amounts, as high solids wastewater. The resultant reject wastewater is noted to have high concentrations of $\mathrm{pH}, \mathrm{COD}$, TDS, and Alkalinity. ${ }^{2}$ The effluents from dye industries are treated by passing through RO and UV process. Most dye industries prefer Reverse Osmosis treatment process as it removes almost $95 \%$ to $99 \%$ of total dissolved solids and recovers almost $60 \%$ of water for recycling. ${ }^{3}$ After passing through the RO process the dissolved solids are forced to separate from the water and are collected as a slurry or concentrate 
These concentrates are dumped into the landfill without any further treatment and they percolate into the soil detrimentally affect the groundwater by contaminating it. ${ }^{4}$

The Brine Reject (RO Reject) if disposed into the water bodies have an impeding effect on aquatic environments. ${ }^{5}$ There are a number of finishing processes in the dyeing industry and every finishing process results in water pollution. It therefore evident that purification of the reject water is necessary before it is let out into the environment. ${ }^{6}$ It was predicted that around the year 2025 almost two-thirds of the world populace would have to face the ill effects of water contamination due to several aspects of pollution and over exploitation of natural resources. It is hence necessary that the concentrate of RO from dye industries should be treated and disposed efficiently as per the regulations of Environmental (Protection) Act. As part of the full treatment process, one of the conventional methods was anaerobic treatment methods as suggested in this research study. Anaerobic biological treatment by anaerobic digesters is used in high BOD effluent water treatment, to further treat auxiliary secondary wastewater; the anaerobic digestion can be employed. After the digestion process, the treated wastewater can be utilized for fertigation process after some post treatment. ${ }^{7}$

An anaerobic baffled reactor (ABR) is used to carry out this anaerobic digestion process. The anaerobic baffled suspended growth reactor is an enhanced septic tank with a progression of perplexes under which the wastewater was compelled to stream over and under the baffles from the inlet to the outlet. The anaerobic baffled reactor keeps up a high void volume without the requirement of filter media. ABR has been successfully used to treat Nitrobenzene wastewater, whisky distillery water, landfill leachate etc. ${ }^{8}$ An anaerobic baffled reactor has the ability to maintain long retention time of solids which is supportive of the bio fermentation process and also, the reactor does not have any moving parts for mechanical blending. ${ }^{9,10}$ The RO Reject was allowed to pass through the reactor and the final effluent from the reactor was analyzed. ${ }^{11-14}$ The secondary treated anaerobic sewage sludge was used as a seeding material in order to enhance the growth of microorganisms for proper anaerobic digestion as rich recycle culture within the reactor. ${ }^{15}$

\section{EXPERIMENTAL}

The initial study of the sample of RO Reject was collected from the common effluent treatment plant of dye industries from Tirupur District which is located at $11.1085^{\circ} \mathrm{N}, 77.3411^{\circ} \mathrm{E}$. The anaerobic sewage sludge which is used as a seeding material for the growth of microorganisms was (collected/sourced) from the Perungudi sewage treatment plant, Chennai which was located at $12^{0} 57^{\prime} 23.5^{\prime \prime} \mathrm{N}, 80^{\circ} 14^{\prime} 02.0^{\prime \prime} \mathrm{E}$. The samples were taken are fed into a small scale anaerobic baffled reactor placed in the Environmental Engineering lab of SRM University, Kattankulathur located at $12.8230^{\circ} \mathrm{N}, 80.0438^{\circ} \mathrm{E}$. The ABR reactor used for treating RO Reject was made up of acrylic material of $5 \mathrm{~mm}$ thickness. It comprises of an arrangement of vertical perplexes that separate it into 5 indistinguishable compartments. Anaerobic sewage sludge is immunized as seeding material. The fluid volume of the reactor was $11 \mathrm{~L}$ and its dimensions are $(35 \times 17 \times 30 \mathrm{~cm})$. A schematic figure of the ABR was represented in Figures-1a and $\mathrm{b}$. the actual picture of lab scale set was presented in Fig.-1b. RO Reject was continuously fed into the reactor with different OLR with the help of a peristaltic pump in order to arrive at the ideal operating conditions of the ABR.

The sewage sludge from the treatment plant needs to be digested for a minimum of 15 days in the absence of oxygen. To achieve this, four recycle stages of digestion process was taken in order to completely digest the sludge. The digested anaerobic sewage sludge was fed into the ABR to increase the growth of microorganisms and enhance a high generation of biogas. Sewage sludge was feed inside the ABR with an incubation period of 60 days.

The RO reject sample was collected from Common Effluent Treatment Plant (CETP) which mainly deals with dye industries from Tirupur in Tamil Nadu. The initial characteristics of the RO reject and activated anaerobic sludge is determined. The ABR was designed and fabricated by using an acrylic material with six baffles. The generation of biogas is monitored during the incubation time as well as during the feed process. After the incubation period, the RO Reject sample was fed into the reactor. The final treated sample is analyzed and the efficiency of the anaerobic baffled reactor was determined. The $\mathrm{pH}$, Total Dissolved Solids (TDS),Total Suspended Solids(TSS),Total Solids(TS), Alkalinity, Chlorides, BOD and 
RASĀYAN J. Chem.

Vol. 10 | No. 4 |1114-1118 | October - December | 2017

COD variations are determined based on the principles of Indian Standard (IS: 3025) and standard methods of examination of water and wastewater based upon APHA standards in vogue. ${ }^{16,17}$

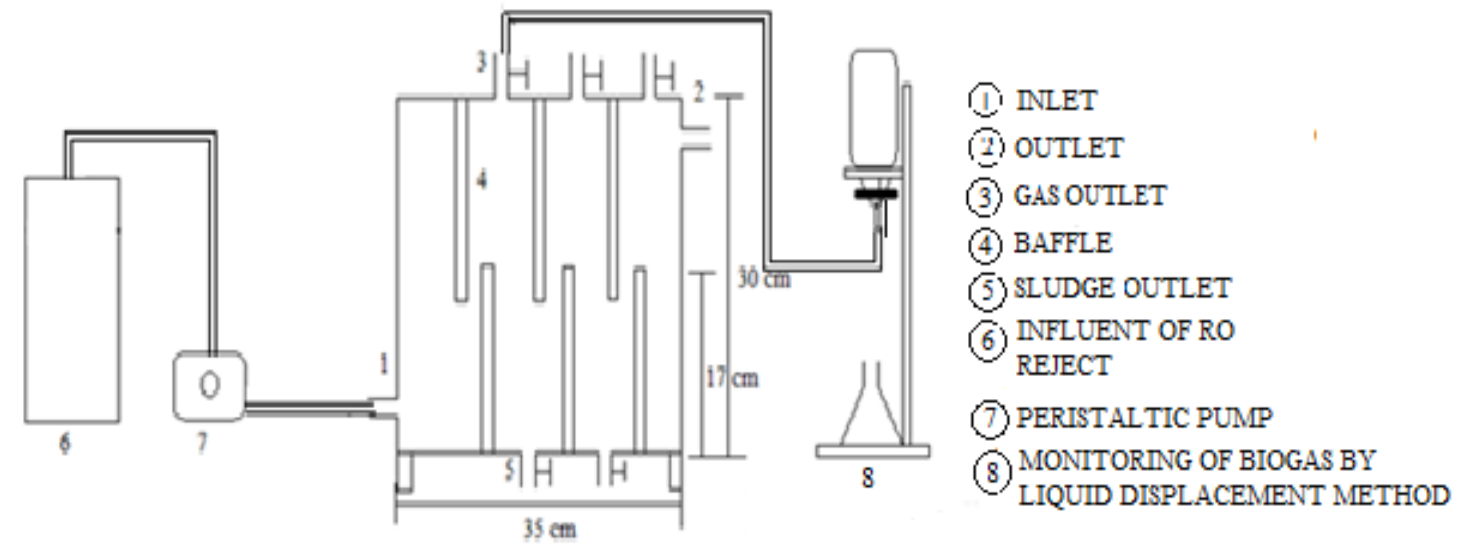

Fig.-1a: Schematic representation of the Anaerobic Baffled Reactor

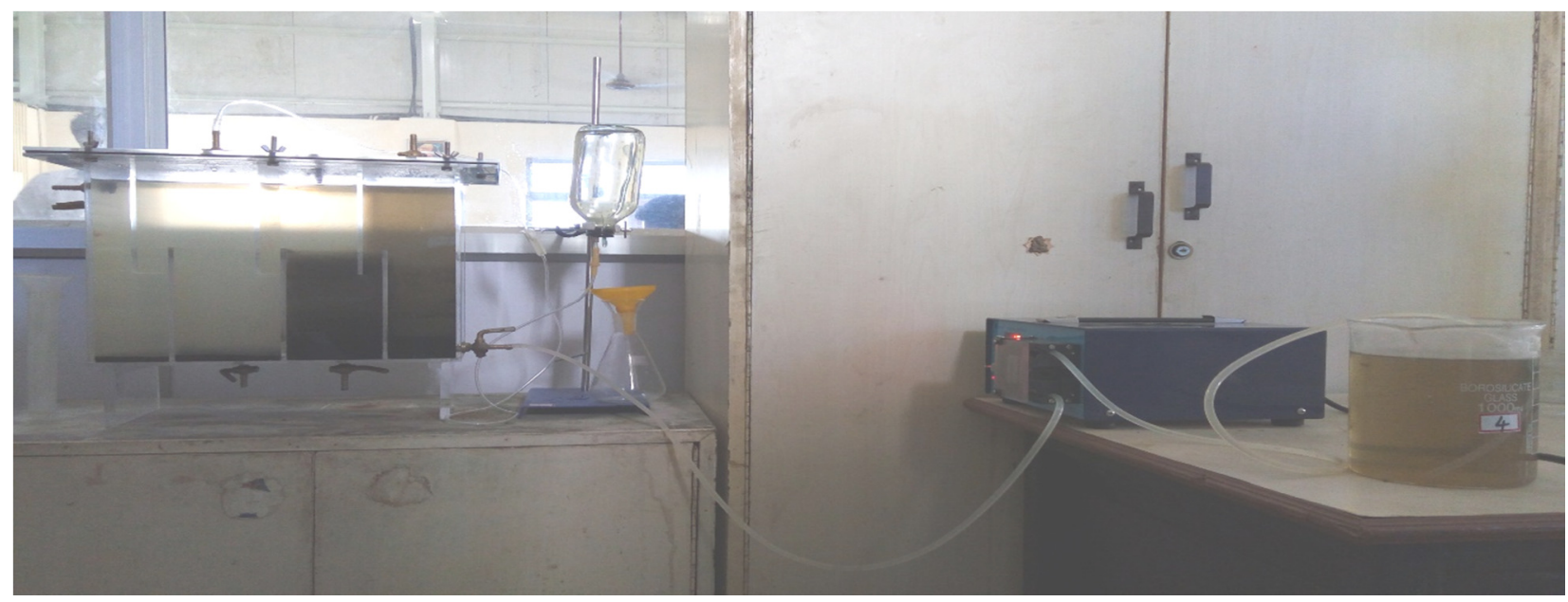

Fig.-1b: Experimental setup of the Anaerobic Baffled Reactor

\section{RESULTS AND DISCUSSION}

The influent wastewater was diluted in a ratio such that the influent COD was reduced to $300 \mathrm{mg} / \mathrm{l}, 600$ $\mathrm{mg} / \mathrm{l}, 800 \mathrm{mg} / \mathrm{l}$ and then the raw influent (RO Reject) $1200 \mathrm{mg} / \mathrm{l} \mathrm{COD}$ was fed into the reactor. The influent wastewater was fed by a peristaltic pump with a hydraulic retention time of 24 hours. ${ }^{15-17}$ After sustaining the influent within the anaerobic baffled suspended growth reactor for a period of 24 hours, the effluent was collected through the outlet and then various parameters are analyzed and the results are represented in Table-1 and 2, and the same was discussed in Figures- 2 and 7.

Table-1: Influent and Effluent Characteristics of RO Reject with Activated Sludge (AS)

\begin{tabular}{c|c|c|c|c|c|c}
\hline S. No. & Parameters & $\begin{array}{c}\text { Initial } \\
\text { Characteristics }\end{array}$ & Influent & Effluent & Influent & Effluent \\
\hline 1 & $\mathrm{pH}$ & 7.20 & 8.00 & 7.65 & 8.06 & 7.71 \\
\hline 2 & $\mathrm{TDS}(\mathrm{mg} / \mathrm{l})$ & 2000 & 10258 & 15987 & 21568 & 26984 \\
\hline 3 & $\mathrm{TSS}(\mathrm{mg} / \mathrm{l})$ & 6000 & 9.00 & 6125 & 15.00 & 7189 \\
\hline 4 & $\mathrm{TS}(\mathrm{mg} / \mathrm{l})$ & 8000 & 10267 & 22112 & 21583 & 34173 \\
\hline 5 & Alkalinity $(\mathrm{mg} / \mathrm{l})$ & 320 & 1324 & 1127 & 2486 & 2167 \\
\hline
\end{tabular}


RASĀYAN J. Chem.

Vol. 10 | No. 4 |1114-1118 | October - December | 2017

\begin{tabular}{c|c|c|c|c|c|c}
\hline 6 & Chloride $(\mathrm{mg} / \mathrm{l})$ & 72 & 5968 & 4125 & 11914 & 8525 \\
\hline 7 & BOD & 570 & 95.00 & 359 & 184 & 482 \\
\hline 8 & COD & 2150 & 284 & 1326 & 539 & 1428 \\
\hline
\end{tabular}

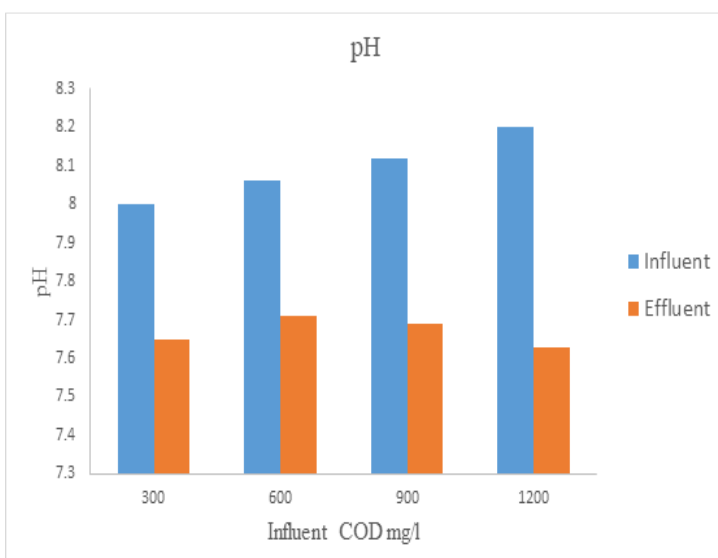

Fig.-2: Characteristics of $\mathrm{pH}$

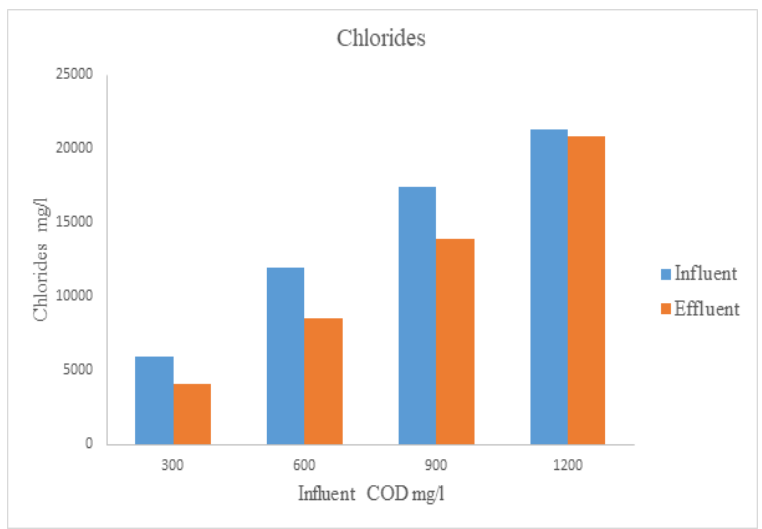

Fig.-4: Characteristics of Chlorides

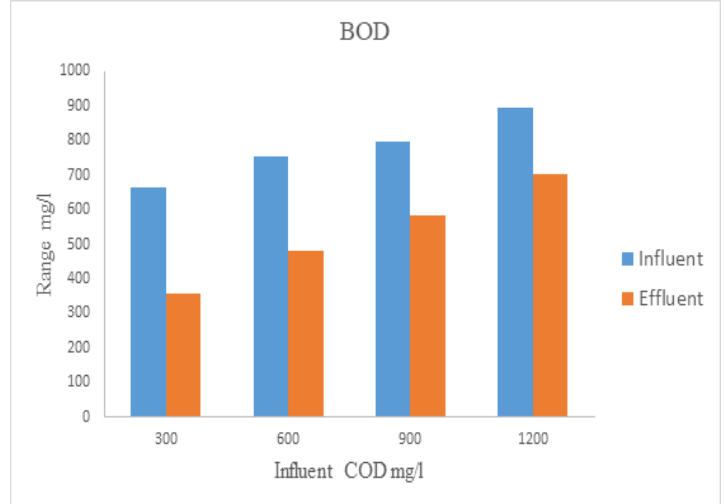

Fig.-6: Characteristics of BOD

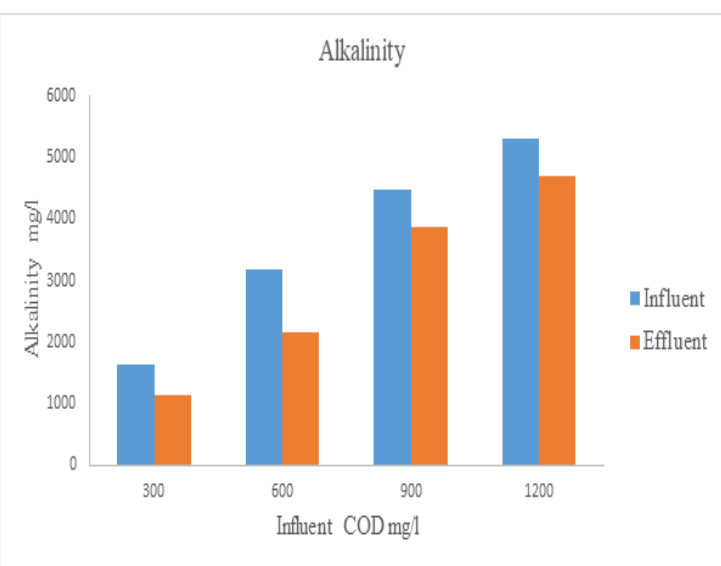

Fig.-3: Characteristics of Alkalinity

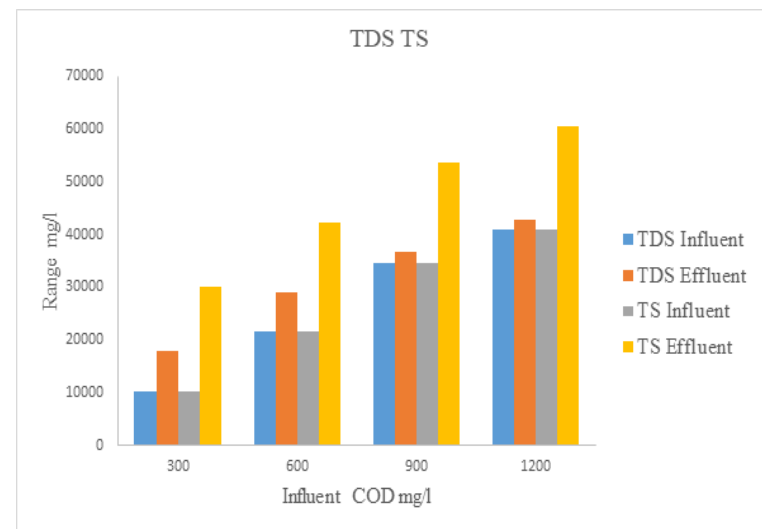

Fig.-5: Characteristics of TDS \& TS

COD

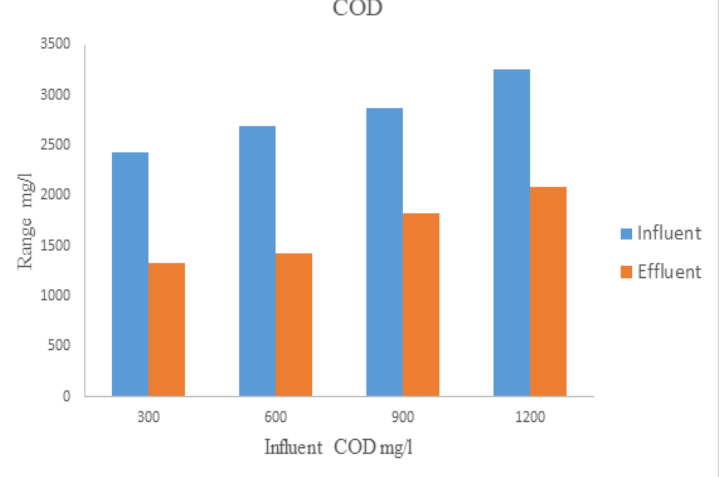

Fig.-7: Characteristics of COD

Table-2: Influent and Effluent Characteristics of RO Reject with Activated Sludge (AS)

\begin{tabular}{c|c|c|c|c|c|c}
\hline S. No. & Parameters & $\begin{array}{c}\text { Initial } \\
\text { Characteristics }\end{array}$ & Influent & Effluent & Influent & Effluent \\
\hline 1 & $\mathrm{pH}$ & 7.20 & 8.12 & 7.69 & 8.20 & 7.63 \\
\hline 2 & $\mathrm{TDS}(\mathrm{mg} / \mathrm{l})$ & 2000 & 34600 & 38597 & 40834 & 45286 \\
\hline
\end{tabular}


RASĀYAN J. Chem.

Vol. 10 | No. 4 |1114-1118 | October - December | 2017

\begin{tabular}{c|c|c|c|c|c|c}
\hline 3 & TSS(mg/l) & 6000 & 24.00 & 6958 & 30.00 & 7258 \\
\hline 4 & TS(mg/l) & 8000 & 34624 & 45555 & 40864 & 52544 \\
\hline 5 & Alkalinity(mg/l) & 320 & 4168 & 3865 & 4974 & 4688 \\
\hline 6 & Chloride (mg/l) & 72 & 17456 & 13856 & 21329 & 20845 \\
\hline 7 & BOD(mg/l) & 570 & 226 & 583 & 324 & 702 \\
\hline 8 & COD(mg/l) & 2150 & 720 & 1824 & 1099 & 2086 \\
\hline
\end{tabular}

It was clear from Figures-2 to 7 , there was a fluctuation in $\mathrm{pH}$ due to the incubation of activated sludge within the baffled reactor. During the incubation period, the biogas is monitored every 24 hours for 60 days and Based on the study using water displacement method on the $23^{\text {rd }}$ day it was noted that COD attain the maximum of $18 \mathrm{mg} / \mathrm{l}$.

\section{CONCLUSION}

The efficiency of removal with high influent concentration was found to be $(55 \%-80 \%)$ of BOD removal, $(65 \%-80 \%)$ of COD removal, $(75 \%-85 \%)$ of alkalinity, $(75 \%-90 \%)$ of chlorides. Treatment of wastewater can be further processed in order to reduce the biological contaminants and make it fit for recycling or fertigation process. Biogas generated can be analyzed by further studying its characteristics so as to improve the efficiency of the treatment process. As there is no efficient treatment method to treat the RO Reject from dye industries, this method can be suggested as one of the pre-treatment methods to reduce the concentration of COD in wastewater. If this study was further improved and used for the treatment of other solids, the recovered water can then be used for various useful processes like Phytoremediation, garden farming, fertilization etc.

\section{REFERENCES}

1 Mohammad Fadhil Abid, Mumtaz Abdulahad Zablouk \& Abir Muhssen Abid-Alameer, Iranian J. of Environmental Health Science and Eng.,9(1), 17 (2012).

2 Sakda Kortangsakul\& Mali Hunsom, Korean J. Chem. Eng., 26(6), 1637(2009).

3 Sung Hee Joe, J. Water Air Soil Pollut.,225(12),2076(2014).

4 R. Boopathy, S.Karthikeyan, A.B. Mandal \& G.Sekaran,J. Clean Tech Environ Policy 15(1),117 (2013).

5 Songbok Lee, Youngjim Kim, Albert.S Kim \& Seungkwan Hong , J. Desalination and Water Treatment,57(16), 7432(2015).

6 D.A Khumbar, International Conference on Advanced Technologies for Societal Applications, 97, (2016).

7 KatarzynaKujawa-Roeleveld\&Grietje Zeeman, Reviews in Environmental Science and Bio Technology, 5(1), 115(2006).

8 Yongqiang Zhu, Dong An, Li-an Hou, Minmin Liu and Shuili Yu, J. Desalination and Water Treatment,57(50), 1(2016).

9 Sebnem Ozdemir, Kevser Cirik, Dilek Akman, Erkan Sahinkaya and Ozer Cinar, J. Bioresource Technology, 146, 135(2013).

10 Ahmed Farghaly, Ahmed Tawfik, J. Appl. Biochem. Biotechnol., 179(2), 204(2016).

11 Quanguo Zhang, Jianjun Hu, Duu-Jong Lee, J. Renewable Energy, 1(12)(2016).

12 Darin Phukingngam, Orathai Chavalparith, Dararath Somchai, Maneerat Ongwande, J. Chemical Papers, 65 (5) 644 , (2011).

13 K. Prasanna and R.Annadurai, Rasayan J. Chem., 9(2), 287(2016).

14 P.Wu, X.Gi, X.Song, Y.Shen, Int. J. Environ. Sci. Technol,11(6), 1611 (2013).

15 S. Dhanasekar and B. Sasivarman, Indian J. Science and Technology, 9(23), 231(2016).

16 IS: 3025, Methods of sampling and test (physical and chemical) for water and wastewater, (2003).

17 Standard Methods for Examination of Water and Wastewater, 20 ed, APHA, Washington D.C, USA (1998).

[RJC-1729/2017] 